\title{
Pengaruh Marketing Public Relation Terhadap Word Of Mouth Communication (Studi Pada Objek Wisata Taman Safari Indonesia Bogor)
}

\author{
Sukmadi' ${ }^{1}$, Maman Usman² \\ Sekolah Tinggi Pariwisata Bandung, Indonesia ${ }^{1,2}$ \\ Email: sukmadi@stp-bandung.ac.id
}

\begin{abstract}
This research was conducted to find (1) the application of marketing public relations, (2) communication word of mouth on the attractiveness of Taman Safari Indonesia, (3) the influence of marketing public relations for word of mouth communication. The method used is quantitative with explanatory research type, which explains the causal relationship between the independent variables on the dependent variable through hypothesis testing. This type of research consists of descriptive and verification conducted through data collection in the field Data collection methods used in the form of a questionnaire measuring instrument method research is conducted with a sample of 46 tourists. This study uses a descriptive analysis of the frequency and method of simple linear regression. The results showed that (1) the relationship public marketing undertaken by manager Taman Safari Indonesia has done well, through publications, events, sponsorship, news, speeches, public service and media activity identity, (2) communication word of mouth carried by tourists so that it can help disseminate information on attractions quickly. This study found that the tourist attractions are also provided recommendations, saying positive things and encourage and influence others to visit the attractions are concerned. (3) There is a significant positive effect between marketing and public relations for the communication word of mouth. This indicates a better marketing, Public Relations better than word of mouth communication about the appeal.
\end{abstract}

Keywords: Marketing Public Relations, Word of Mouth Communication

\begin{abstract}
Abstrak
Penelitian ini dilakukan untuk mengetahui (1) penerapan pemasaran public relations, (2) komunikasi word of mouth terhadap daya tarik Taman Safari Indonesia, (3) pengaruh public relations pemasaran untuk komunikasi word of mouth. Metode yang digunakan adalah kuantitatif dengan jenis penelitian eksplanatori, yang menjelaskan hubungan kausal antara variabel independen terhadap variabel dependen melalui pengujian hipotesis. Jenis penelitian ini terdiri dari deskriptif dan verifikasi yang dilakukan melalui pengumpulan data di lapangan. Metode pengumpulan data yang digunakan berupa kuesioner yaitu alat ukur metode penelitian yang dilakukan dengan sampel sebanyak 46 wisatawan. Penelitian ini menggunakan analisis deskriptif frekuensi dan metode regresi linier sederhana. Hasil penelitian menunjukkan bahwa (1) hubungan pemasaran publik yang dilakukan oleh pengelola Taman Safari Indonesia telah dilakukan dengan baik, melalui publikasi, acara, sponsor, berita, pidato, layanan publik dan identitas aktivitas media, (2) komunikasi dari mulut ke mulut yang dilakukan oleh wisatawan sehingga bahwa itu dapat membantu menyebarkan informasi tentang atraksi dengan cepat. Studi ini menemukan bahwa tempat wisata juga memberikan rekomendasi, mengatakan hal-hal positif dan mendorong serta mempengaruhi orang lain untuk mengunjungi tempat wisata yang bersangkutan. (3) Ada pengaruh positif yang signifikan antara pemasaran dan hubungan masyarakat untuk komunikasi dari mulut ke mulut. Ini menunjukkan pemasaran yang lebih baik, Hubungan Masyarakat lebih baik daripada komunikasi dari mulut ke mulut tentang daya tarik.
\end{abstract}

Kata kunci: Hubungan Masyarakat Pemasaran, Komunikasi Word of Mouth

\section{A. PENDAHULUAN}

Sektor pariwisata memiliki peran yang penting dalam perekonomian Indonesia, baik sebagai salah satu sumber penerimaan devisa maupun membuka kesempatan kerja dan 
kesempatan berusaha. Selain itu berkembangnya sektor pariwisata di suatu wilayah dapat memicu perkembangan pada sektor-sektor lainnya, seperti bidang pertanian, peternakan, perkebunan, kerajinan dan lainnya.Hal ini tidaklah berlebihan rnengingatpotensi kepariwisataan yang ddimiliki Indonesia cukup besar, bahkan banyak diantaranya belum dimanfatkan secara optimal terutama menyangkut wisata alam, wisata minat khusus dan wisatabudaya. Pariwisata adalah salah satu industri andalan yang harus terus ditumbuh kembangkan oleh suatu negara. Hal ini disebabkan selain terbukti ampuh menyumbang devisa secara signifikan, juga dapat memperluas kesempatan kerja dan pemerataan penduduk (Agusnawar, 2002). Devisa bagi suatu negara merupakan faktor yang sangat penting, terutama bagi negara-negara berkembang yang sedang melaksanakan berkewajiban mengurusi urusan rumah tangganya sendiri-sendiri, hampir semua daerah di Indonesia berlomba- lomba untuk memperkenalkan keunikan, kekayaan (baik alam, budaya, maupun buatan manusia) serta cirri khas daerahnya dalam rangka menarik wisatawan untuk berkunjung.

Salah satu daerah tujuan wisata yang memiliki potensi wisata yang perlu dikembangkan ialah Taman Safari Indonesia. Taman Safari Indonesia terletetak di Kabupaten Bogor yang dibangun untuk tujuan sebagai objek wisata alam. Untuk meningkatkan kunjungan wisatawan ke Taman Safari Indonesia maka diperlukan suatu promosi. Promosi merupakan suatu hal yang penting dalam pengembangan pariwisata. Salah satu alat promosi yang dapat dilakukan adalah melalui marketing public relation. Marketing Public Relations (MPR) adalah proses merencanakan, melaksanakan dan mengevaluasi program yang mendorong pembelian dan kepuasan pengunjung melalui komunikasi informasi dan impresi yang kredibel. Seperti halnya iklan, hubungan masyarakat (public relations) juga menjadi kiat pemasaran penting. MPR memberikan nilai tambah terhadap program komunikasi pemasaran terpadu dalam beberapa cara, yaitu membangun daya tarik pasar sebelum munculnya periklanan di media, sebagai contoh, pemberitaan mengenai produk baru yang merupakan suatu peluang bagi para pemasar untuk mendapatkan publisitas dan mendramatisasikan produk tersebut sehingga akan meningkatkan keefektifan dari iklan tersebut.

Menyadari akan pentingnyaperanan MPR dalam rangka menciptakan word of mouth communication yang positif bagi perusahaan, maka MPR harus dapat menjadi informan yang baik bagi perusahaan. Selain itu, praktisi MPR juga harus tanggap dalam mengamati, mempelajari, dan menyelesaikan suatu masalah, baik masalah yang timbul dari dalam maupun dari luar perusahaan. MPR akan memahami kondisi perusahaan, apabila perusahaan memberikan kesempatan kepada MPR untuk menerima masukan, mengolahnya, dan kemudian mengintegrasikannya dengan program dari perusahaan. Hal ini bertujuan agar MPR dapat memberikan informasi yang berimbang, komunikatif, dan mendidik bagi publik eksternal.

Walaupun demikian penerapan strategi marketing public relation pada pengunjung objek wisata Taman Safari Indonesia diduga belumlah optimal. Hal tersebut dikarenakan kurangnya prom osi yang dilakukan oleh objek wisata sehingga mengakibatkan kinerja marketing public relation belum sesuai dengan yang diharapkan. Selain daripada itu, kurangnya publikasi yang dilakukan oleh objek wisata mengenai potensi yang ada pada objek wisata menyebabkan kurang maksimalnya kinerja marketing public relation. Oleh karena itu diperlukan langkah-langkah untuk mengatasi permasalahan tersebut. Pada dasamya marketing public relation yang dilakukan dengan baik dapat menciptakan word of mouth communication yang positif.

Saat ini kekuatan word of mouth mulai disadari dan dimanfaatkan olehbanyak perusahaan, mengingat iklan-iklan di mediamassa tidak lagi efektif sebagai alat promosi karenakonsumen hanya bisa mengingat lima sampai tujuhiklan per hari (Schiffman dan Kanuk, 2008). Word ofaiouth lebih dipercaya dibandingkan oleh seorang salesperson, dan dapat menjangkau konsumen lebih cepatdaripada iklan maupun direct-mail, karena kekuatan word of mouth terletak pada kemampuannya dalam memberikan 
rekomendasi (referral). Hal ini sejalan dengan apa yang dinyatakan Dye (2000) bahwa dalam kehidupan sehari-hari orang senang sekali untuk membagi pengalamannya tentang sesuatu. Dengan demikian word of mouth communication merupakan suatu alat komunikasi non formal yang memiliki peranan cukup penting dalam meningkatkan kunjungan wisatawan ke objek wisata tertentu.

Permasalahan yang berkaitan dengan word of mouth communication ialah pada umumnya word of mouth communication yang dilakukan wisatawan belumlah efektif dalam meningkatkan kunjungan wisatawan pada objek wisata yang bersangkutan.

Hal ini dikarenakan kuantitas komunikasi yang dilakukan oleh wisatawan pada orang lain sangatlah minim, tingkat rekomendasi oleh wisatawan untuk berkunjung pada objek wisata masih kurang serta terdapat kesan negatif dimana objek wisata tidak terawat dengan bersih sehingga menghambat efektivitas kinerja word of mouth cornmamication itu sendiri.

Berdasarkan uraian di atas maka penelitian ini memiliki beberapa tujuan diantaranya adalah sebagai berikut:

1. Untuk mengetahui dan menganalisis marketing public relation pada objek wisata Taman Safari Indone sia.

2. Untuk mengetahui dan menganalisis word of mouth communication pada objek wisata Taman Safari Indonesia.

3. Untuk mengetahui dan menganalisis pengaruh marketing public relation terhadap word of mouth communication pada objek wisata Taman Safari Indonesia.

\section{B. METODE PENELETIAN}

Penelitian mengenai pengaruh antara marketing public relation dengan word of mouth communication merupakan penelitian kuantitatif dengan jenis penelitian penjelasan (explanatory research) yang menjelaskan hubungan kausal antara variabel independen terhadap variabel dependen melalui pengujian hipotesis. Jenis penclitian ini terdiri dari deskriptif dan verifikatif yang dilaksanakan tnelalui pengumpulan data di lapangan.

Adapun teknik pengumpulan data yang dilakukan penulis dalam penelitian ini adalah (1) observasi, (2) Wawancara, (3) Kuesioner. Sedangkan analisis data yang digunakan terdiri dari deskriptif dan verifikatif dengan regressi. Dalam penelitian ini terdapat satu variabel dependent dan satu variabel independent. Berdasarkan hal tersebut maka metode analisis yang digunakan adalah regresi sederhana, yang persamaannya dapat dikemukakan sebagai berikut:

$$
\begin{aligned}
& \text { K eterangan: } \\
& \begin{array}{l}
\mathrm{Y}=\mathrm{WOM} \\
\mathrm{X}=M P R \\
\mathrm{a}=\text { konstantan regresi } \\
\mathrm{b}=\text { koefisien regresi } \\
\mathrm{e}=\text { error }
\end{array}
\end{aligned}
$$$$
\mathrm{Y}=\mathrm{a}+\mathrm{bX}+\mathrm{e}
$$ 


\section{HASIL DAN ANALISIS}

\section{Gambaran Deskriptif Data Penelitian}

Data hasil tanggapan responden diuraikan dalam bentuk gambar untuk mengetahui proporsi tanggapan responden pada masing-masing butir pernyataan yang selanjutnya diinterpretasikan sesuai dengan teori-teori yang mendasarinya.

\section{Hasil Analisis Deskriptif Marketing Public Relation}

Hasil penelitian yang merupakan jawaban responden atas 16 pertanyaan yang diajukan dalam kuesioner marketing public relation sebagai berikut:

Tabel 1: Frekuensi Jawaban Marketing Public Relation

\begin{tabular}{|c|c|c|c|c|c|c|}
\hline \multirow[t]{2}{*}{ No. } & \multicolumn{5}{|c|}{ Frekuensi Jawaban } & \multirow[t]{2}{*}{ Jumlah } \\
\hline & 5 & 4 & 3 & 2 & 1 & \\
\hline $\mathrm{p} 1$ & 13 & 22 & 3 & 5 & 3 & 46 \\
\hline $\mathrm{p} 2$ & 5 & 24 & 8 & 7 & 2 & 46 \\
\hline p3 & 5 & 35 & 2 & 2 & 2 & 46 \\
\hline $\mathrm{p} 4$ & 7 & 17 & 12 & 8 & 2 & 46 \\
\hline p5 & 8 & 23 & 9 & 4 & 2 & 46 \\
\hline p6 & 10 & 22 & 5 & 7 & 2 & 46 \\
\hline p7 & 13 & 24 & 3 & 4 & 2 & 46 \\
\hline p8 & 2 & 23 & 13 & 5 & 3 & 46 \\
\hline p9 & 11 & 22 & 3 & 7 & 3 & 46 \\
\hline $\mathrm{p} 10$ & 10 & 18 & 5 & 9 & 4 & 46 \\
\hline $\mathrm{P} 11$ & 14 & 23 & 4 & 5 & 0 & 46 \\
\hline $\mathrm{p} 12$ & 4 & 26 & 7 & 9 & 0 & 46 \\
\hline $\mathrm{p} 13$ & 5 & 28 & 8 & 3 & 2 & 46 \\
\hline $\mathrm{p} 14$ & 7 & 18 & 13 & 8 & 0 & 46 \\
\hline $\mathrm{p} 15$ & 9 & 23 & 10 & 4 & 0 & 46 \\
\hline p16 & 10 & 21 & 5 & 10 & 0 & 46 \\
\hline Jumlah & 133 & 367 & 110 & 97 & 27 & 736 \\
\hline \multirow[t]{2}{*}{ No. } & \multicolumn{5}{|c|}{ Skor Jawaban } & \multirow[t]{2}{*}{ Jumlah } \\
\hline & 5 & 4 & 3 & 2 & 1 & \\
\hline 11 & 65 & 88 & 9 & 10 & 3 & 175 \\
\hline 12 & 25 & 96 & 24 & 14 & 2 & 161 \\
\hline 13 & 25 & 140 & 6 & 4 & 2 & 177 \\
\hline 14 & 35 & 68 & 36 & 16 & 2 & 157 \\
\hline 15 & 40 & 92 & 27 & 8 & 2 & 169 \\
\hline 16 & 50 & 88 & 15 & 14 & 2 & 169 \\
\hline 17 & 65 & 96 & 9 & 8 & 2 & 180 \\
\hline 18 & 10 & 92 & 39 & 10 & 3 & 154 \\
\hline 19 & 55 & 88 & 9 & 14 & 3 & 169 \\
\hline 20 & 50 & 72 & 15 & 18 & 4 & 159 \\
\hline 21 & 70 & 92 & 12 & 10 & 0 & 184 \\
\hline 22 & 20 & 104 & 21 & 18 & 0 & 163 \\
\hline 23 & 25 & 112 & 24 & 6 & 2 & 169 \\
\hline 24 & 35 & 72 & 39 & 16 & 0 & 162 \\
\hline 25 & 45 & 92 & 30 & 8 & 0 & 175 \\
\hline
\end{tabular}




\begin{tabular}{|c|r|r|r|r|r|c|}
\hline 26 & 50 & 84 & 15 & 20 & 0 & 169 \\
\hline Jumlah & 665 & 1476 & 330 & 194 & 27 & 2348 \\
\hline & & & & & & \\
\hline
\end{tabular}

Untuk mengkategorikan penilaian dari responden terhadap kuesioner marketing public relation, sesuai dari basil jawaban diatas maka penulis membuat pengkategorian dalam garis interval sebagai berikut:

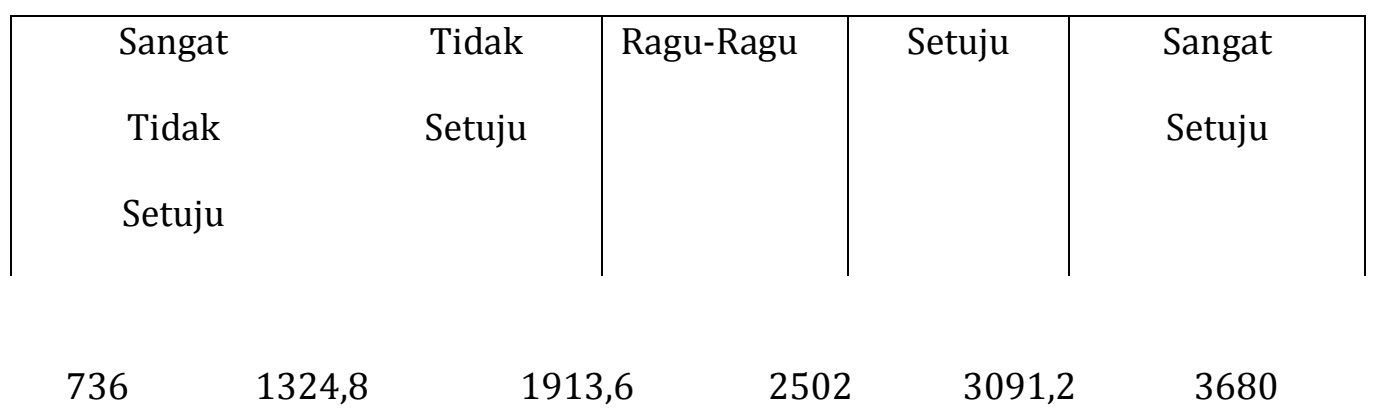

Skor total dari keenam belas item pertanyaan di atas diperoleh skor total sebesar 2348 masuk dalam kategori"Setuju". Hasil penelitian ini menunjukkan bahwa marketing public relation yang dilakukan oleh pengelola objek wisata Taman Safari Indonesia sudah dilakukan dengan baik. Marketing public relation dilakukan melalui publikasi, event-event, sponsorship, news, speeches, public services activities dan identity media. Publikasi media dilakukan untuk meraih dan mempengaruhi target market dan dilakukan melaui berbagai media termasuk di dalamnya brosur, artikel dan majalah perusahaan. Objek wisata Taman Safari Indonesia juga melakukan event-event untuk menarik minat wisatawan untuk berkunjung ke objek wisata. Melalui event-event ini dapat membantu penyebaran informasi dengan lebih efektif tepat pada sasarannya.

Dalam melakukan sponsorship maka objek wisata mempromosikan identitas perusahaan dengan mere spon kegiatan olahraga dan acara seni. Melalui adanya sponsorship ini membantu memperlancar kegiatan promosi yang dilakukan oleh objek wisata. Pengelola objek wisata juga menginformasikan objek wisata melalui berita dengan jelas sehingga informasi yang diberikan dapat diterima dengan baik oleh wisatawan yang berkunjung pada objek wisata. Pemberitaan mengenai objek wisata ini dilakukan melalui berbagai media baik cetak maupun elektronik. Disamping itu, pengelola objek wisata memberikan pidato kepada wisatawan dengan jelas dan akurat sehingga informasi yang diberikan oleh pengelola objek wisata dapat dipahami dengan baik.

Untuk lebih meningkatkan efektivitas pemasaran maka pengelola objek wisata melakukan aktivitas pelayanan umum kepada wisatawan yang berkunjung pada objek wisata tersebut. Aktivitas pelayanan umum dilakukan agar objek wisata memperoleh kesan balk dari wisatawan dan hal tersebut membantu dalam memperkenalkan objek wisata pada wisatawan. Marketing public relation yang dilakukan oleh pengelola objek wisata dilengkapi dengan logo-logo dan slogan sebagai identitas perusahaan sehingga diharapkan lebih dikenal oleh masyarakat. Identitas perusahaan yang diperkenalkan kepada wisatawan memiliki identitas yang jelas sehingga mudah diketahui oleh masyarakat. 


\section{Hasil Analisis Dskriptif Word of Mouth Communication}

Hasil penelitian merupakan jawaban responden yang atas 9 pertanyaan pertanyaan yang diajukandalam kuesioner word of mouth communication sebagai berikut:

Tabel 2

Frekuensi Jawaban Word ofMouth Communication

\begin{tabular}{|c|r|r|r|r|r|c|}
\hline \multirow{2}{*}{ No. } & \multicolumn{7}{|c|}{ Frekuensi Jawaban } & \multirow{2}{*}{ Jumlah } \\
\cline { 2 - 6 } & 5 & 4 & 3 & 2 & 1 & \\
\hline p1 & 10 & 27 & 6 & 3 & 0 & 46 \\
\hline p2 & 10 & 21 & 8 & 7 & 0 & 46 \\
\hline p3 & 2 & 38 & 4 & 2 & 0 & 46 \\
\hline p4 & 2 & 23 & 15 & 6 & 0 & 46 \\
\hline p5 & 14 & 23 & 4 & 5 & 0 & 46 \\
\hline p6 & 0 & 34 & 10 & 2 & 0 & 46 \\
\hline p7 & 4 & 33 & 7 & 2 & 0 & 46 \\
\hline p8 & 15 & 22 & 4 & 5 & 0 & 46 \\
\hline p9 & 5 & 27 & 10 & 4 & 0 & 46 \\
\hline Jumlah & 62 & 248 & 68 & 36 & 0 & 414 \\
\hline No. & \multicolumn{7}{|c|}{ Skor Jawaban } & & Jumlah \\
\cline { 2 - 6 } & 5 & 4 & 3 & 2 & 1 & \\
\hline il & 50 & 108 & 18 & 6 & 0 & 182 \\
\hline i2 & 50 & 84 & 24 & 14 & 0 & 172 \\
\hline i3 & 10 & 152 & 12 & 4 & 0 & 178 \\
\hline i4 & 10 & 92 & 45 & 12 & 0 & 159 \\
\hline i5 & 70 & 92 & 12 & 10 & 0 & 184 \\
\hline i6 & 0 & 136 & 30 & 4 & 0 & 170 \\
\hline i7 & 20 & 132 & 21 & 4 & 0 & 177 \\
\hline i8 & 75 & 88 & 12 & 10 & 0 & 185 \\
\hline i9 & 25 & 108 & 30 & 8 & 0 & 171 \\
\hline Jumlah & 310 & 992 & 204 & 72 & 0 & 1578 \\
\hline
\end{tabular}

Untuk mengkategorikan penilaian dari responden terhadap kuesioner word of mouth communication, sesuai dari hasil jawaban di atas maka penulis membuat pengkategorian dalam garis interval sebagai berikut:

1578

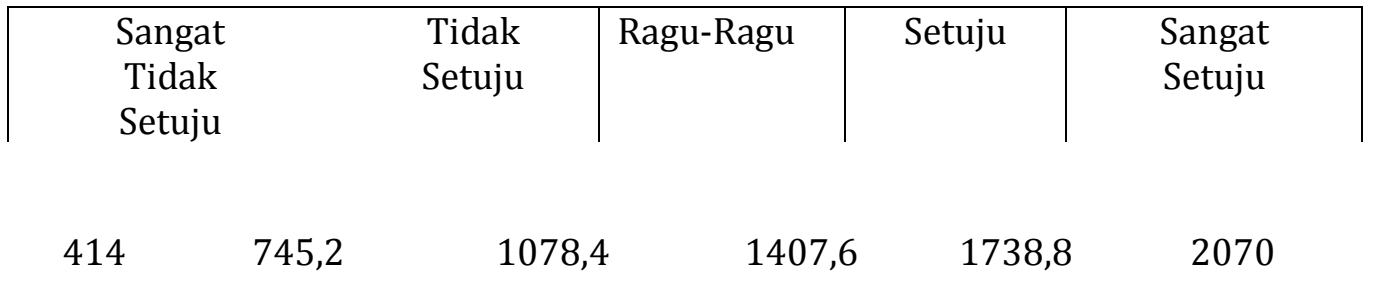


Skor total pertanyaan disebesar 1578 "Setuju". Hasil dari kesembilan item atas diperoleh skor total masuk dalam kategori ini menunjukkan bahwa wisatawan selalu memiliki pandangan yang positif tentang objek wisata. Pandangan positif selalu disebarkan melalui word of mouth communication yang positif dari wisatawan yang telah berkunjung pada objek wisata pada pihak lainnya. Di dalam percakapan sehari- hari wisatawan sering menyebutkan nama Taman Safari Indonesia sehingga dapat teringat dengan baik di benak wisatawan. Kemttdian wisatawan sering melakukan diskusi tentang Taman Safari Indonesia dengan orang lain sehingga pihak lain tersebut sangat penasaran untuk mengunjungi objek wisata.

Tingkat rekomendasi yang dilakukan oleh wisatawan kepada pihak lain sangat intensif. Hal tersebut sangat membantu terhadap promosi yang dilakukan oleh objek wisata untuk menarik minat wisatawan untuk berkunjung pada objek wisata yang direkomendasikan oleh pihak lain tersebut. Wisatawan juga menceritakan hal-hal positif pada orang lain sehingga hal tersebut akan membentuk citra positif pada objek wisata yang dikunjungi wisatawan. Selanjutnya, objek wisata juga dapat membentuk keyakinan wisatawan untuk mengunjungi Taman Safari Indonesia sehingga membuat wisatawan tertarik pada objek wisata tersebut.

Hasil penelitian berikutnya menunjukkan bahwa wisatawan selalu mengajak dan membujuk wisatawan lain untuk berkunjung pada objek wisata tersebut dan mendorong orang lain untuk pergi berlibur ke Taman Safari Indonesia. Hal ini dikarenakan para wisatawan yang telah berkunjung ke objek wisata memperoleh kepuasan tersendiri setelah mengunjungi objek wisata tersebut baik itu dari segi pelayanan maupun event-event yang diselenggarakan oleh objek wisata. Para wisatawan juga selalu mempengatuhi orang lain agar berkunjung pada objek wisata Taman Safari Indonesia dikarenakan hal tersebut. Kemudian para wisatawan juga menginginkan agar orang lain dapat menikmati segala sarana dan fasilitas yang disediakan oleh objek wisata Taman Safari Indonesia. Hal tersebut dikarenakan wisatawan memiliki persepsi positif terhadap objek wisata yang bersangkutan.

\section{Hasil Analisis Regressi}

Hasil analisis regresi linier berganda dengan program SPSS ver 15 for windows dimaksudkan untuk menganalisis tentang besarnya pengaruh dari variabel MPR terhadap WOM yaitu dengan melihat besar koefisien dete2minasi (R Square). Dalam penelitian ini terdapat 1 (satu) variabel dependent dan 1 (satu) variabel independent. Berdasarkan hal tersebut maka metode analisis yang digunakan adalah simple regression. Dan analisa regresi yang dilakukan dengan menggunakan bantuan Program SPSS ver 15 for windows', hasil olah data dapat terlihat seperti tabel 3 berikut:

Tabel 3

Analisa Regresi

\begin{tabular}{|c|l|r|r|r|r|r|}
\hline \multicolumn{2}{|c|}{ Model } & B & $\begin{array}{l}\text { Unstandardized } \\
\text { Coefficients } \\
\text { SW Frror }\end{array}$ & $\begin{array}{c}\text { Standardized } \\
\text { Coefficients } \\
\text { Beta }\end{array}$ & t & Sig. \\
\hline 1 & (Constant) & 63,936 & 9,183 & & 6,962 &, 000 \\
\hline & MPR &, 669 &, 156 &, 604 & 4,290 &, 000 \\
\hline
\end{tabular}


a. Dependent Variable: WOM

Keterangan:

$\mathrm{Y}=\mathrm{WOM}$

$\mathrm{X}=\quad$ MPR

Berdasarkan tabel di atas, maka persamaan regresi yang di dapat adalah sebagai berikut: $\mathrm{Y}=$ $63,936+0,669 \mathrm{X}$

Persamaan model matematis di atas menunjukkan bahwa marketing public relationberpengaruh terhadap word of mouth communication. Hal itu ditunjukkan dari koefisien regresi manajemen resiko yaitu positif 0,669. Berdasarkan tabel 3 tersebut diatas, dapat dilihat bahwa nilai probabilitas signifikansi atau p value-nya adalah 0.000 atau lebih kecil dari 0.05 atau $5 \%$ dan koefisien regresi-nya adalah positif 0.669 yang artinya hipotesis yang berbunyi marketing public relation berpengaruh positif dan signifikan terhadap word of mouth communication dapat dibuktikan.

Sedangkan untuk mengukur seberapa jauh kemampuan variabel bebas dalam menerangkan variabel yang terikat digunakan uji koefisien detenninasi dari harga $\mathrm{R}^{2}$. Perhitungan regresi hasil olah data SPSS ditunjukkan pada tabel 4 berikut ini:

Tabel 4: Koefisien Determinasi

\begin{tabular}{|c|c|c|c|c|}
\hline Model & R & R Square & R Square & $\begin{array}{c}\text { Adjusted Error } \\
\text { of the } \\
\text { Estimate }\end{array}$ \\
\hline 1 &, $604(\mathrm{a})$ &, 365 &, 345 & 6,30832 \\
\hline
\end{tabular}

a Predictors: (Constant), MPR

Berdasarkan tampilan output SPSS model summary, besamya adjusted $\mathrm{R}^{2}$ adalah 0,345 , hal ini berarti $34,5 \%$ variabel dependen word of mouth communication dapat dijelaskan atau dipengaruhi oleh

\section{Hasil Penelitian}

Hasil penelitian menunjukkan bahwa marketing public relation yang dilakukan oleh pengelola objek wisata Taman Safari Indonesia sudah dilakukan dengan baik. Marketing public relation dilakukan oleh pengelola objek wisata Taman Safari Indonesia melalui publikasi, event-event, sponsorship, news, speeches, public services activities dan identity media. Marketing public relations merupakan salah satu cara dari enam cara komunikasi utama pemasaran yang sangat penting peranan dan tugas-tugasnya. Marketing public relations merupakan suatu perencanaan, pelaksanaan dan pengevaluasian programprogram yang dapat merangsang pembelian dan kepuasan konsumen melalui pengomunikasian informasi, yang dapat dipercaya dan melalui kesan-kesan positif yang ditimbulkan dan berkaitan dengan variabel independen marketing public relation, sedangkan sisanya 64,5\% (100\%-34,5\%) dijelaskan oleh scbab-sebab yang lain di luar model ini.

Identitas perusahaan atau produknya sesuai dengan kebutuhan, keinginan, perhatian dan kepentingan bagi para konsumen. (Rosady Ruslan, 2006:245). Marketing public relations yang kreatif dapat mempengaruhi kesadaran masyarakat hanya dengan biaya yang jauh lebih kecil dari pada biaya iklan. Perusahaan tersebut tidak membayar ruang dan waktu 
yang diperoleh dalam media. Perusahaan hanya membayar seorang staf untuk menyusun dan mengedarkan cerita dan mengelola acara- acara tertentu. Peranan marketing public relations dalam upaya mencapai tujuan perusahaan secara garis besamya adalah mcmbangun kesadaran konsumen atas produk yang ditawarkan, membangun kepercayaan, mendorong pembelian, menekan biaya promosi dan efektif didalam menghadapi suatu situasi atau kejadian yang menimbulkan anggapan negatif sehingga upaya untuk memperbaiki kembalianggapan negatif tersebut dapat dilakukan dengan tepat dan hubungan baik denganberbagai publik pentsahaan dapat dipertahankan. Berdasarkan hal tersebut maka marketing public relations sangat penting untuk mempromosikan objek wisata kepada calon wisatawan.

Sementara itu, word of mouth communication yang dilakukan oleh wisatawan dapat membantu menyebarkan informasi tentang objek wisata secara cepat. Wisatawan selalu memiliki pandangan yang positif tentang objek wisata. Pandangan positif ini selalu disebarkan melalui word of mouth communication yang positif dari wisatawan yang telah berkunjung pada objek wisata pada pihak lainnya sehingga sangat efektif sebagai alat dalam mempromosikan objek wisata. WOM memiliki kekuatan yang lebih besar dibandingkan dengan ilclan atau penjualan langsung karena kekuatan WOM terletak pada kemampuannya dalam memberikan rekomendasi (referral). WOM mendapat perhatian khusus dari konsumen karena dipersepsikan sebagai kredibel dan orang menyampaikan WOM dianggap hanya memberikan infonnasi dan membagi pengalamannya dalam mengkonsumsi suatu produk/jasa tanpa memiliki kepentingan apa-apa terhadap penjualan produk/jasa tersebut. George (2001:25).

Alasan lain mengapa WOM sangat penting peranannya dalam pemasaran suatu produk adalah karena WOM mampu meningkatkan kecepatan keputusan pembelian produk. WOM membuat proses itu menjadi lebih cepat, karena apa yang dibicarakan dalam WOM berdasarkan atas pengalaman terhadap produk atau jasa tersebut sehingga konsumen akan cenderung mempercaya inya.

Hasil penelitian berikutnya menunjukkan bahwa terdapat pengaruh yang positif dan signifikan antara marketing public relation terhadap word of mouth communication. Hal tersebut dapat dilihat dari nilai probabilitas signifikansi (sig.) atau p value-nya sebesar 0,000 atau lebih kecil dari 0,05 (5\%) dan koefisien regressinya adalah 0,669 . Hasil penelitian tersebut sesuai dengan yang dikemukakan oleh Mechinda (2010:222) yang menyatakan faktor-faktordaya saing dan jumlah tujuan wisatawan berpengaruh positif terhadap loyalitas dan word of mouth wisatawan menuju Koh Chang (Chan g Island).

Dari basil penelitiansangat jelas bahwa faktor daya saing memiliki pengaruh terhadap word of mouth wisatawan sehingga akan terbentuk persepsi wisatawan dari objek wisata tertenttt. Senada dengan hal tersebut maka Urosovic (2010:1315) menyatakan bahwa budaya pariwisata, tujuan pemasaran dan strategi pengembangan melalui marketing \& public relation berpengaruh positif pada word of mouth budaya kepariwisataan. Oleh karena itu, terdapat keterkaitan antara marketing public relation dengan word of mouth communication.

Dari hasil penelitian tersebut diketahui bahwa dengan dimensi dari marketing public relation seperti pemberitaan dan publikasi yang gencar, simultan dan berkelanjutan terhadap suatu daerah tujuan wisata ternyata mampu memberikan kepercayaan dan komitmen wisatawan terhadap daerah tujuan wisata tersebut sehingga tercipta word of mouth dari wisatawan terhadap daerah tujuan wisata tersebut yang membuat hubungan antara wisatawan dengan daerah tujuan wisata menjadi meningkat dan lebih berkualitas. 


\section{E. SIMPULAN}

Didasarkan atas basil penelitian yang dilakukan untuk mengetahui pengaruh antara marketing public relation terhadap word of mouth communication serta pembahasan yang telah diuraikan sebelumnya, maka dapat ditarik beberapa kesimpulan. Marketing public relation yang dilakukan oleh pengelola objek wisata Taman Safari Indonesia sudah dilakukan dengan baik. Marketing public relation ini dilaksanakan melalui publikasi, event-event, sponsorship, news, speeches, public services activities dan identity media.

Word of mouth communication yang dilakukan oleh wisatawan dapat membantu menyebarkan informasi tentang objek wisata secara cepat. Wisatawan memberikan rekomendasi pada pihak lain tentang objek wisata Taman Safari Indonesia, menceritakan hal-hal positif dan mendorong serta mempengaruhi pihak lain untuk berkunjung ke objek wisata yang bersangkutan.

Terdapat pengaruh positif dan signifikan antara marketing public relation terhadap word of mouth communication. Hal ini menunjukkan semakin baik marketing public relation $\mathrm{m}$ aka semakin baik pula word of mouth communication tentang objek wisata tersebut.

\section{DAFTAR PUSTAKA}

Agus Nawar. 2002. Psikologi Pelayanan. Bandung: Alfabeta.

Belch, George E., and Belch: Michael A. 2009. Advertising and Promotion: an Integrated, Mark.

Blackwell, R. D. 2001. Customer Behaviour (9th Ed) Orlando: Hardcourt. College.

Dye, Renee. 2000. The Buzz on Buzz. Harvard Business Review, 78 (6).

Godes,David dan Dina Mayzlin. 2004. Using Online Conversations to Study Word of Mouth Communication. Marketing Science. Vol. 23 No. 4.

Grunig, James E., dan Larissa E. Grunig. 2008. Models of Public Relations and Communication dalam Excellence in Public Relations and Communication Management. Jakarta: New Jersey: Lawrence Erlbaum Associates, Inc.

Harris, Thomas L. 2008. The Marketers Guide to Public Relations. New York: John. Wiley \& Sons, Inc.

Indriantoro dan Supomo. 2009. ivietodologi Penelitian Bisnis. Yogyakarta, BPFE-Yogyakarta

Jang, Dongsuk. 2003. Effect of Word of Mouth Communication on Purchasing Decession in Restaurant. Dissertation. Las Vegas University of Nevada

Kaplanidou, Kiki. 2009. The Role of Word-of-Mouth and How It Can Be Used to Develop a Competitive Advantage For a Destination. Journal Travel Michigan and MSU Department of Park, Recreation and Tourism Resources.

Malholtra, Naresh. 2010. Marketing Research an Applied Orientation. 6thtEdition.Prentice Hall.

Matos. 2008. Word-of-mouth communications in marketing: a meta-analytic review of the antecedents and moderators. Journal Marketing Department, School of Management, Federal University of Rio Grande do Sul.

Ruslan, Rosady. 2006. Kiat dan Strategi Kampanye Public Relations(Revisi). Jakarta: Raja Grafindo Persada.

Schiffman, Leon, \&Kanuk, Leslie Lazar. 2008. Consumer $\quad$ Behaviour $\quad$ 7i'Edition. $\quad$ (Perilaku Konsumen). Jakarta: PT. Indeks.

Sekaran, Uma. 2003. Research Methods for Business. USA: John Wiley \& Sons, Inc.

Shimp, Terence. 2009, PeriklananPromosi. Jakarta: Erlangga. Sugiyono. 2008. Metode PenelitianBisnis. Bandung: Alfabeta

Tercia, Ch. Yosevina Ratna. 2008. Sikap Kewirausahaan dan Orientasi Pelanggan: Implikasinya terhadap Kinerja Tenaga Penjualan. Manajemen Usahawan Indonesia. No.04. TII. XXXVII 2008. 
Pengaruh Marketing Public Relation Terhadap Word Of Mouth Communication (Studi Pada Objek Wisata Taman Safari Indonesia Bogor)

Sukmadi, Maman Usman

Umar, Husen. 2002. Metode Penelitian. Jakarta:Salemba Empat

Woznaik. 2001. Consumer Behavior and Applied Approach. Prentice Hall: New Jersey. 